\title{
Magnesium Sulphate Therapy in Women with Pre-Eclampsia and Eclampsia in Kuwait
}

\author{
A.E. Omu ${ }^{\mathrm{a}, \mathrm{c}}$ J.Al-Harmi ${ }^{\mathrm{a}, \mathrm{c}}$ H.L. Vedi ${ }^{\mathrm{b}}$ L. Mlechkova ${ }^{\mathrm{b}} \quad$ A.F. Sayed ${ }^{\mathrm{c}}$ \\ N.S. Al-Ragum ${ }^{c}$ \\ a Department of Obstetrics and Gynaecology, Faculty of Medicine, Kuwait University, and Departments of \\ ${ }^{\mathrm{b}}$ Anaesthesia and ${ }^{\mathrm{C} O b s t e t r i c s}$ and Gynaecology, Maternity Hospital, Kuwait
}

\section{Key Words}

Magnesium sulphate therapy $\cdot$ Pre-eclampsia $\cdot$ Eclampsia

\begin{abstract}
Objective: To evaluate the outcome of the use of $\mathrm{MgSO}_{4}$ therapy in women with severe pre-eclampsia in Kuwait from January 2002 to December 2004. Subjects and Methods: The study involved 450 women managed at the Maternity Hospital in Kuwait with a blood pressure of $160 / 110 \mathrm{~mm} \mathrm{Hg}$ and proteinuria of $>0.3-5 \mathrm{~g} / 24 \mathrm{~h}$. A loading dose of $4 \mathrm{~g}$ $\mathrm{MgSO}_{4}$ was administered intravenously over $20 \mathrm{~min}$ and then the maintenance dose continued at $1 \mathrm{~g} / \mathrm{h}$ for $24 \mathrm{~h}$ postpartum. Magnesium sulphate toxicity was monitored by urine output, deep tendon reflexes and serum magnesium levels and managed with an infusion of $10 \mathrm{ml}$ of $10 \%$ calcium gluconate and cessation of magnesium infusion. Adjunct therapy included intravenous hydralazine $10 \mathrm{mg}$ and labetalol $100 \mathrm{mg}$. The mode of delivery was determined after stabilizing the patient. Results: The women included Kuwaitis $(n=200,44.4 \%)$, Asians $(n=129,28.7 \%)$ and other Arabs $(n=$ $116,25.8 \%$ ) with a mean age of $29.7 \pm 6.7$ years (primigravida: $n=233,51.8 \%$; other parities: $n=217,48.2 \%)$. Antenatal complications included intra-uterine growth restriction $(\mathrm{n}=$ $136,30.2 \%)$, oliguria $(n=39,8.7 \%)$, haemolysis, elevated liver enzymes and low platelet count syndrome $(n=30,6.6 \%)$, abruptio placentae $(n=20,4.4 \%)$, eclampsia $(n=15,3.3 \%)$,
\end{abstract}

and preterm birth ( $n=253,55.2 \%)$. Caesarean section $(n=$ $241,53.6 \%$ ) was the main mode of delivery. The perinatal mortality rate was 27 per 1,000. Magnesium sulphate toxicity observed as reduced tendon reflexes occurred in 14 (3.1\%) patients and flushing, nausea and vomiting and blocked nostrils in 86 (19.1\%). There was no association between adverse outcomes and maternal serum magnesium concentrations and no maternal mortality occurred. Conclusion: Magnesium sulphate was effective in preventing recurrence of eclamptic fits and safe for both mother and fetus.

Copyright $\odot 2008$ S. Karger AG, Basel

\section{Introduction}

Pre-eclampsia is a major complication of pregnancy, affecting $5-10 \%$ of all pregnancies. It is a disorder of the placenta with multisystem involvement that leads to severe maternal morbidity and mortality from associated renal, haematological, hepatic and cerebral impairment, with oliguria, haemolysis and eclamptic fits [1] and an exaggerated inflammatory response and inappropriate endothelial activation, and with microthrombus formation that further compromises blood flow to organs [2]. Eclampsia complicates 1 in 100-1,700 pregnancies in the developing countries and 1 in 2,000 pregnancies in the developed world, with more than 50,000 maternal deaths

\section{KARGER}

Fax +4161306 1234

E-Mail karger@karger.ch

www.karger.com
(C) 2008 S. Karger AG, Basel

$1011-7571 / 08 / 0173-0227 \$ 24.50 / 0$

Accessible online at:

www.karger.com/mpp
Dr. Alexander E. Omu

Department of Obstetrics and Gynaecology

Faculty of Medicine, HSC, Kuwait University

PO Box 24923, Safat 13110 (Kuwait)

Tel. +965 498 6458, Fax +965 533 8906, E-Mail Omu@hsc.edu.kw 
worldwide each year, mostly in developing countries, and causes high perinatal mortality from intra-uterine growth restriction and iatrogenic preterm delivery in the interest of the mother and the fetus.

The prevention of eclamptic fits has been based on the perceived contemporaneous cause of the disorder [6]. Renal decapsulation, fluid drainage, implantation of ureters into the colon, mastectomy and oophorectomy were common modalities of treatment before the 18th century. Thereafter, stomach lavage, and high colonic flushings and phlebotomy were in vogue. Stroganoff introduced sedation with morphine sulphate and chloral hydrate in 1930 and various anticonvulsant drugs such as diazepam, phenytoin, chlormethiazole, barbiturates and lytic cocktail came into use, but with resultant severe side-effects and a high rate of recurrent eclamptic fits [7, 8]. In 1924, Lazard [9] successfully used magnesium sulphate to treat eclamptic seizures. Concerns about the potential side-effects and toxicity of magnesium sulphate and safety of the parturient and the fetus as well as a lack of understanding of the mechanism of action prevented its worldwide use.

There is currently a better understanding of the mechanisms of action of magnesium sulphate in regulating the neuromuscular excitability by acting directly on the myoneural function by antagonizing N-methyl-D-aspartate receptor activation [10-14]. Consequently, many studies have been carried out on the efficacy and safety of magnesium sulphate compared with placebo such as phenytoin and diazepam in the treatment of pre-eclampsia and eclampsia [15-17]. Recurrence of seizures has been found to be less common with magnesium sulphate therapy compared with phenytoin and diazepam, with a reduction in maternal mortality. With the worldwide menace of pre-eclampsia/eclampsia, a call for international action was therefore inevitable $[18,19]$. The Magpie Trial Collaborative Group [5] was an elegant response to this call; in this study, involving 175 hospitals in 33 countries worldwide, 10,141 women with pre-eclampsia were enrolled. The study was stopped by the data monitoring board earlier than planned as results from the first 8,483 women showed such a strong benefit of magnesium sulphate with 58\% less likely to progress to eclampsia and $45 \%$ less likely to die in childbirth compared with placebo-treated women, but there was no difference between the two groups in the risk of newborn deaths $[5,20]$. In this account, we report the evaluation of the outcome of the use of $\mathrm{MgSO}_{4}$ in the Maternity Hospital in Kuwait from January 1, 2002 to December 31, 2004. The study was approved by the Ethics Committee of the Hospital.

\section{Subjects and Methods}

\section{Patients}

This is a prospective descriptive study, involving 450 women admitted with severe pre-eclampsia or eclamptic fits, who received magnesium sulphate therapy and delivered at the Maternity Hospital during the study period. The Maternity Hospital is the biggest maternity unit in Kuwait and the obstetric and gynaecological teaching hospital of Kuwait University, catering for over $40 \%$ of deliveries in the country with an annual delivery rate of 14,000 . Magnesium sulphate therapy to abort eclamptic fits and prevent recurrence was started at the hospital in 1998. In 2002, a database including all data connected with pre-eclampsia was started.

Inclusion criteria were: (1) severe pre-eclampsia: blood pressure $\geq 160 / 110 \mathrm{~mm} \mathrm{Hg}$ sustained $6 \mathrm{~h}$ apart, elevated blood pressure plus proteinuria $0.3-5 \mathrm{~g} / 24 \mathrm{~h}$, massive oedema, oliguria $<500$ $\mathrm{ml}$, systemic symptoms like pulmonary oedema, headaches, diplopia, right upper quadrant pain, elevated liver enzymes or low platelet count; (2) eclampsia: verifiable history of fits at home, on the way to the hospital or inside the hospital, while all cases of epilepsy, encephalopathy, tetanus, meningitis, hypoglycaemia, keto-acidosis and pyrexia were excluded.

\section{Clinical Examination of the Patients}

On admission, each patient was subjected to clinical examination which included history of the present pregnancy and its management. The gestational age was usually calculated from the last normal menstrual period and confirmed by ultrasound at about 18-22 weeks of gestation. Relevant past obstetric, medical, surgical, drug, social and family histories were reviewed. Physical examination included general health of the patient, blood pressure estimation with Korotkoff phase 4 for the diastolic blood pressure, examination of the gravid uterus to exclude intra-uterine growth restriction, and fetal lie and presentation. Every patient had initial baseline investigations such as complete blood count for haemoglobin and haematocrit, white blood cells and platelets; renal function tests including electrolytes, urea, creatinine, and uric acid; liver function tests for elevated aspartate transaminase, alanine transaminase and lactate dehydrogenase; coagulation profile (elevated prothrombin time, partial thromboplastin time and fibrinogen degradation products), 24-hour urine for creatinine clearance and total amount of protein in the urine, and serum magnesium level.

Initial fetal examination and continuous fetal monitoring was carried out in each patient. If the patient was admitted with a history of previous eclamptic fits or had fulminating pre-eclampsia, she was immediately admitted to the intensive care unit and given magnesium sulphate intravenously.

\section{Protocol for Administration of Magnesium Sulphate}

The loading dose was $4 \mathrm{~g}$ i.v. over $20 \mathrm{~min}$ and then the maintenance dose continued at $1 \mathrm{~g} / \mathrm{h}$ for at least $24 \mathrm{~h}$ after delivery. Magnesium sulphate therapy was aggressively monitored with urinary output (>120 $\mathrm{ml}$ in $4 \mathrm{~h}$ ), deep tendon reflexes and serum magnesium levels.

Magnesium sulphate toxicity was indicated by loss of reflexes and drowsiness, poor urine output and high serum magnesium levels and treatment used included an antidote in the form of an infusion of $10 \mathrm{ml}$ of $10 \%$ calcium gluconate; in addition, magnesium sulphate infusion would be stopped for 1-2 h. 
Adjunct Therapy: Antihypertensive Therapy

The first-line therapy was with hydralazine $10 \mathrm{mg}$ i.v. slowly, and a repeat dose of $5 \mathrm{mg}$ i.v. after $20 \mathrm{~min}$, and the second-line drug used was labetalol, starting with 50-100 mg i.v. slowly.

\section{Timing of Delivery}

All the 450 patients with pre-eclampsia, antenatal eclamptic fits, and other complications gave birth as soon as the fits and high blood pressure were controlled. The choice of the mode of delivery depended largely on the Bishop score: if it was favourable (i.e. $\geq 7$ ), induction of labour was initiated; however, if the Bishop score was $<7$, immediate caesarean section was carried out; 351 women had induction of labour. Data about obstetric and neonatal outcome of the general maternity population during the study period were collected for comparison.

\section{Statistical Analysis}

Data were analysed with Statview software. Mean \pm SD was calculated for paired values. Differences among groups were estimated by the Student $t$ test. The Mann-Whitney test was used for data from unpaired groups of observations, and $\chi^{2}$ statistics with Yates' correction, approximation of Katz and linear regression analysis were applied when appropriate. Significance was set at $\mathrm{p}=0.05$.

\section{Results}

Of the 33,162 total deliveries during the 3-year study period, 1,283 (3.9\%) were complicated by pregnancy-induced hypertension defined as a blood pressure of 140/90 $\mathrm{mm} \mathrm{Hg}$ starting after 20 weeks of gestation and persistent $6 \mathrm{~h}$ apart. Magnesium sulphate was administered to 450 (35.1\%) women with severe pre-eclampsia and 15 (1.1\%) who developed eclamptic fits out of the women with pregnancy-induced hypertension; 15 women out of the 450 (3.3\%) with severe pre-eclampsia also developed eclampsia. The characteristics of the study patients compared with their counterparts in the maternity population are listed in table 1. Severe pre-eclampsia was significantly more common among non-Kuwaitis $(\mathrm{n}=250,55.6 \%)$ compared to Kuwaitis $(\mathrm{n}=200,44.4 \%$; OR $=1.82,95 \%$ CI $1.087-2.285, \mathrm{p}<0.004)$. Women in the age range of $31-40$ years $(n=208,46.3 \%)$ were more likely to have severe preeclampsia compared with younger and older counterparts $(\mathrm{OR}=1.55,95 \%$ CI $1.40-1.71, \mathrm{p}<0.001)$, especially in their first pregnancy. Primigravidity had an important association with pre-eclampsia $(\mathrm{OR}=2.20,95 \%$ CI 2.01 $2.41, \mathrm{p}<0.001)$. Significantly more pre-eclamptic women delivered much earlier than the general population (35.4 vs. 38.9 weeks, $\mathrm{p}<0.05$ ), with 56.2 versus $7.8 \%$ having preterm delivery (below 30 weeks of gestation: $\mathrm{OR}=6.11$, 95\% CI 4.56-8.19, p < 0.001; between 30 and 36 weeks of gestation: $\mathrm{OR}=7.49,95 \%$ CI $6.73-8.34, \mathrm{p}<0.001)$. As summarized in table 2 , there were differential manifesta-
Table 1. Socio-demographic characteristics of the patients

\begin{tabular}{lcc}
\hline & $\begin{array}{l}\text { Pre- } \\
\text { eclamptics }\end{array}$ & $\begin{array}{l}\text { General } \\
\text { maternity }\end{array}$ \\
\hline Ethnicity & & \\
Kuwaitis & $200(44.4)$ & $17,576(53)$ \\
Non-Kuwaitis & $250(55.6)$ & $15,586(47)$ \\
Asians & $129(28.7)$ & - \\
Non-Kuwaiti Arabs & $116(25.8)$ & - \\
Others & $5(1.1)$ & - \\
Age (mean \pm SD), years & $29.7 \pm 6.7$ & $29.4 \pm 5.8$ \\
Age group & & \\
$\quad \leq 20$ & $30(6.6)$ & $2,951(8.9)$ \\
$\quad 21-30$ & $212(47.1)$ & $22,770(59.7)$ \\
$\quad 31-40$ & $208(46.3)$ & $9,915(29.9)$ \\
$\quad>40$ & - & $497(1.5)$ \\
Parity (mean \pm SD) & $1.24 \pm 0.34$ & - \\
$\quad 0$ & $233(51.7)$ & $7,793(23.5)$ \\
$\quad 1-4$ & $137(41.1)$ & $19,101(57.6)$ \\
$\quad \geq 5$ & $32(7.2)$ & $6,268(18.9)$ \\
Gestation at delivery & & \\
(mean \pm SD), weeks & $35.4 \pm 3.8$ & $38.9 \pm 1.8$ \\
$<30$ & $44(9.8)$ & $531(1.6)$ \\
$30-36$ & $209(46.4)$ & $2,056(6.2)$ \\
$37-40$ & $197(43.8)$ & $25,004(75.4)$ \\
$>40$ & - & $5,571(16.8)$ \\
\hline
\end{tabular}

Figures in parentheses indicate percentages. 253 (56.2\%) women had preterm delivery; 351 (78\%) had induction of labour but $142(40.6 \%)$ were delivered with caesarean section.

Table 2. Antenatal complications of pre-eclampsia on admission to the intensive care unit

\begin{tabular}{lc}
\hline & Patients \\
\hline High blood pressure $\geq 160 / 110 \mathrm{~mm} \mathrm{Hg}$ & $450(100)$ \\
Proteinuria & $450(100)$ \\
Headaches & $180(40)$ \\
Epigastric pain & $75(16.7)$ \\
Blurred vision & $62(13.8)$ \\
IUGR & $136(30.2)$ \\
Oliguria & $39(8.7)$ \\
HELLP syndrome & $30(6.6)$ \\
Abruptio placentae & $20(4.4)$ \\
Eclampsia & $10(2.2)$ \\
\hline
\end{tabular}

Figures in parentheses indicate percentages. Other patients with eclampsia: 3 intrapartum and 2 postpartum.

IUGR = Intra-uterine growth restriction; HELLP = haemolysis, elevated liver enzymes, low platelet count. 
Table 3. Outcome of magnesium sulphate therapy

\begin{tabular}{lc}
\hline Side-effects & \\
\hline Toxicity with reduced tendon reflexes & $14(3.1)$ \\
Other features (flushing, nausea and vomiting, & \\
$\quad$ blocked nostrils and headaches) & $86(19.1)$ \\
Days of ICU stay & \\
$\leq 2$ & $316(70.2)$ \\
$3-4$ & $97(21.6)$ \\
$5-6$ & $23(5.1)$ \\
$>6$ & $14(3.1)$ \\
Postnatal complications (causes of long stay in the ICU $\geq 4$ days) \\
Persistent hypertension & $47(10.4)$ \\
Massive generalized oedema & $32(7.1)$ \\
Low platelet count (<50,000) & $28(6.2)$ \\
Wound haematoma & $25(5.5)$ \\
Infection (chest, UTI, wound) & $19(4.2)$ \\
Transient blindness & $4(0.8)$ \\
Disseminated intravascular coagulopathy & $4(0.8)$ \\
Recurrent seizures & $1(0.2)$ \\
\hline
\end{tabular}

Figures are numbers, with percentages in parentheses. ICU = Intensive care unit; UTI = urinary tract infection.

tions of fulminating pre-eclampsia such as headaches, epigastric pain, and blurred vision. Intra-uterine growth restriction occurred in $136(30.2 \%)$ of the women, while 39 (8.7\%) had oliguria defined as urinary output of less than $25 \mathrm{ml} / \mathrm{h}$. In $30(6.6 \%)$ women, there was evidence of haemolysis, elevated aspartate and alanine transaminases and low platelet count $(<50,000 / \mathrm{dl})$.

\section{Outcome of Magnesium Sulphate Therapy}

As shown in table 3, magnesium sulphate toxicity manifested by reduced tendon reflexes was observed in 14 (3.1\%) women. Two (0.4\%) patients had eclamptic seizures while on $\mathrm{MgSO}_{4}$ therapy. Other side-effects including flushing, nausea and vomiting and blocked nostrils were cumulatively demonstrated in $86(19.1 \%)$ of the women; $316(70.2 \%)$ stayed in the intensive care unit for less than $48 \mathrm{~h}, 413$ (92\%) for 4 days or less but 14 (3.1\%) women for more than 6 days. The reasons for the prolonged stay in the intensive care unit included persistent hypertension, generalized oedema, and low platelet count resulting in wound haematoma. Four women had transient blindness. There was no maternal mortality.

\section{Obstetric Outcome}

Two hundred and forty women (53.6\%) of the preeclamptic women were delivered by caesarean section
$(\mathrm{OR}=2.71,95 \% \mathrm{CI} 2.48-2.96, \mathrm{p}<0.001)$. Assisted vaginal delivery with forceps/vacuum was also more common in pre-eclamptic women than women in the general maternity population without pre-eclampsia $(\mathrm{OR}=1.90,95 \%$ CI $1.39-2.62, \mathrm{p}<0.01)$. Significantly more pre-eclamptic women gave birth to babies with a birth weight of less than $1,000 \mathrm{~g}(\mathrm{OR}=7.32,95 \%$ CI $5.05-10.60, \mathrm{p}<0.001)$ or below $2.5 \mathrm{~kg}(\mathrm{OR}=6.59,95 \%$ CI 6.00-7.23, $\mathrm{p}<0.001)$. Pre-eclampsia was more significantly associated with intra-uterine growth restriction than the general maternity population ( $\mathrm{OR}=4.82,95 \% \mathrm{CI} 4.28-5.46, \mathrm{p}<0.01)$ : low Apgar score of $1-3$ (OR $=3.64,95 \%$ CI 3.26-4.28, p < $0.001)$ and Apgar score of $4-6(\mathrm{OR}=3.84,95 \%$ CI $3.34-$ $3.98, \mathrm{p}<0.01)$.

Of the 15 women with eclamptic fits, 10 (66.7\%) had them antenatally, 3 (20\%) intrapartum and 2 (13.3\%) postpartum including 1 (6.7\%) with recurrent seizures. Their mean age was $24.8 \pm 2.6$ years (range 20-31), with an admission blood pressure of 130/80-200/120 mm Hg and proteinuria of $0.8 \pm 0.4 \mathrm{~g} / \mathrm{day}$ (range $0.3-5.0$ ); gestation on admission and delivery was $35.2 \pm 1.4$ weeks (range 25-39 weeks of gestation). Most of the eclamptic women $(n=9,75 \%)$ were delivered by caesarean section. The mean birth weight was $2.5 \pm 0.4 \mathrm{~kg}$ (range 0.650 $3.050 \mathrm{~kg}$ ) and there was 1 intra-uterine fetal death and 1 early neonatal death from severe pre-eclampsia. Duration of stay in the intensive care unit was $2.4 \pm 0.3$ days mainly due to the need to complete magnesium sulphate therapy. The mean duration of hospitalization was $4.8 \pm$ 0.8 days (range $4-6$ days).

Magnesium sulphate toxicity was evaluated in 14 preeclamptics and 40 women on $\mathrm{MgSO}_{4}$ without reduction of deep tendon reflexes (1.9 vs. $1.8 \mathrm{mM}$ ) and in 2 eclamptics with reduced tendon reflexes compared to 13 without (2.1 vs. $1.9 \mathrm{nM}$ ) while on $\mathrm{MgSO}_{4}$ therapy. There were no significant differences between the groups in the serum Mg concentrations.

\section{Discussion}

Although 450 women treated with $\mathrm{MgSO}_{4}$ had severe pre-eclampsia/eclampsia, there was neither life-threatening maternal morbidity nor mortality. Minor side-effects included flushing and signs of magnesium sulphate toxicity with recurrence. The safety of magnesium in this study was probably facilitated by limiting the loading dose of magnesium to $4 \mathrm{~g}$ and the maintenance dose to 1 $\mathrm{g} / \mathrm{h}$ by intravenous route, as recommended by the Royal College of Obstetricians and Gynaecologists evidence- 
based guidelines for the management of eclampsia [21]. Although the serum magnesium levels were essentially higher in those with reduced tendon reflexes, the difference did not reach the level of significance when compared with their counterparts without reduced tendon reflexes. Clinical assessment is therefore as important as serum magnesium sulphate levels for monitoring magnesium sulphate toxicity, as most serious complications of magnesium sulphate therapy are usually a result of human errors [22]. The findings of this study that only 2 $(0.4 \%)$ women had eclamptic seizures while on $\mathrm{MgSO}_{4}$ therapy and no maternal mortality confirm the report of the Eclampsia Collaborative Trial of 9,966 women from 33 countries that $\mathrm{MgSO}_{4}$ therapy in eclampsia reduced maternal morbidity and deaths [23]. The present study also confirms the Cochrane review [24] of 6 clinical trials involving 11,444 women showing that magnesium sulphate more than halved the risk of eclampsia and maternal death [20].

Magnesium sulphate therapy in pre-eclampsia has not been associated with improved neonatal outcome in the short-term [5, 23-25]. There are many confounding factors that contribute to adverse neonatal outcome, and therefore make the evaluation of the neonatal outcome after magnesium sulphate therapy difficult, such as primigravidity (52\%), preterm delivery in 56 and $53 \%$ of preeclamptic and eclamptic women, respectively, and intrauterine growth restriction among $30.2 \%$ of the women in the present study. In the Magpie study [5], more than 53\% of the babies were born underweight (less than $2.5 \mathrm{~kg}$ ). One should, however, take into account that most cases of perinatal morbidity in pre-eclampsia usually occur very remote in time from the exposure to $\mathrm{MgSO}_{4}$. Riaz et al. [26] evaluated the effects of maternal magnesium sulphate treatment on newborn infants delivered at $\geq 34$ weeks of gestation whose mothers received a minimum of $12 \mathrm{~h}$ of intravenous $\mathrm{MgSO}_{4}$, and beyond the immediate postdelivery period, there were no additional complications in this cohort attributable to prenatal $\mathrm{MgSO}_{4}$ exposure. This has recently been confirmed by the follow-up of 4,483 children of the Magpie Trial [27] at 18 months after exposure of their mothers to $\mathrm{MgSO}_{4}$. There was no increased risk of death or disability.

Like the present study, two studies at the Rotunda Hospital in Dublin [28] and the Yorkshire region of the UK involving 16 maternity units using a common guideline of $\mathrm{MgSO}_{4}$ therapy for pre-eclampsia for a 5-year prospective study [29] confirmed the outcome. There were no maternal deaths but about $72 \%$ of these women were delivered by lower segment caesarean section and the mean birth weight was $2.54 \mathrm{~kg}$ due to intra-uterine growth restriction and preterm delivery. In a recent economic evaluation of the Magpie trial by Simon et al. [30], $\mathrm{MgSO}_{4}$ therapy for pre-eclampsia was found to cost less and prevent eclampsia, especially in low gross national income countries. Cost-effectiveness substantially improved if magnesium sulphate was used for severe pre-eclampsia. From the results of the present study and the foregoing review, there is compelling evidence of the safety and effectiveness of $\mathrm{MgSO}_{4}$ therapy for pre-eclampsia/eclampsia.

\section{Conclusion}

Magnesium sulphate is safe for the mother and fetus, used as an anticonvulsant in severe pre-eclampsia and eclampsia reducing maternal morbidity and mortality and cost of care. The prevalence of magnesium sulphate toxicity was very mild. Monitoring is important in the protocol for magnesium sulphate therapy to diagnose toxicity early and to treat it using antidote calcium gluconate.

\section{References}

1 Sibai BM: Diagnosis and management of gestational hypertension and preeclampsia. Obstet Gynecol 2003;102:181-192.

-2 Azria E, Tsatsaris V, Goffinet F, Kayem G, Mignon A, Cabrol D: Magnesium sulfate in obstetrics: current data. J Gynecol Obstet Biol Reprod 2004;33:510-517.

-3 Douglas KA, Redman CWG: Eclampsia in the United Kingdom. Lancet 1994;309:13951399. $\checkmark 4$ World Health Organization International Collaborative Study of Hypertensive Disorders of Pregnancy: Geographic variation in the incidence of hypertension in pregnancy. Am J Obstet Gynecol 1988;158:80-83.

5 The Magpie Trial Collaborative Group: Do women with pre-eclampsia, and their babies, benefit from magnesium sulphate? The Magpie Trial: a randomized placebo-controlled trial. Lancet 2002;359:1877-1890.
6 Loudon I: Some historical aspects of toxaemia of pregnancy. A review. Br J Obstet Gynecol 1991;98:853-858.

-7 Omu AE, al-Othman S, al-Qattan F, al-Falah FZ, Sharma P: A comparative study of obstetric outcome of patients with pregnancy induced hypertension: economic considerations. Acta Obst Gynecol Scand 1996;75: 443-448. 
$>8$ Hutton JD, James DK, Stirrat GM, Douglas KA, Redman CWG: Management of severe preeclampsia and eclampsia by UK consultants. Br J Obstet Gynaecol 1992;99:554556.

9 Lazard EM: A preliminary report on intravenous use of magnesium sulphate in puerperal eclampsia. Am J Obstet Gynecol 1952;9: 178-188.

10 Romani A, Scarpa A: Regulation of cell magnesium. Arch Biochem Biophys 1992;298:112.

11 Gunther T, Hollriegl V, Vormann J, Classen HG: Vitamin E, iron content and lipid peroxidation in tissues of $\mathrm{Mg}$-sufficient and $\mathrm{Mg}$-deficient rats treated with streptozocin and insulin. Magnesium Bull 1995;2:52-55.

12 Yang X: Magnesium-induced vasodilatation from blockade of calcium entry into vascular smooth muscle, antagonism of calcium activity, and release of nitric oxide and prostacyclin. Am J Physiol 2000;103:R628.

13 Fawcett WJ, Haxby EJ, Male DA: Magnesium: physiology and pharmacology. $\mathrm{Br} \mathrm{J}$ Anaesth 1999;83:302-320.

14 Lu JF, Nightingale CH: Magnesium sulphate in eclampsia and preeclampsia: pharmacokinetic principles. Clin Pharmacokinet 2000;38:305-314

15 Lucas MJ, Leveno KJ, Cunningham FG: A comparison of magnesium sulfate with phenytoin for the prevention of eclampsia. N Engl J Med 1995;333:201-206.
16 Chien PF, Khan KS, Arnott N: Magnesium sulphate in the treatment of eclampsia and preeclampsia: an overview of the evidence from randomized trials. Br J Obstet Gynaecol 1996;103:1085-1091.

17 Witlin AG, Sibai BM: Magnesium sulphate therapy in preeclampsia and eclampsia. Obstet Gynecol 1994;92:883-889.

18 Coetzee EJ, Dommisse J, Anthony J: A randomized controlled trial of intravenous magnesium sulphate versus placebo in the management of women with severe preeclampsia. Br J Obstet Gynaecol 1998;105: 300-303

19 Sheth SS, Chalmers I: Magnesium for preventing and treating eclampsia: time for international action. Lancet 2002;359:18721873.

20 Rozenberg P: Magnesium sulphate for the management of preeclampsia. Gynecol Obstet Fertil 2006;34:54-59.

21 Royal College of Obstetricians and Gynaecologists: Guidelines: management of eclamp sia. http://www.rcog.org.uk (accessed July 12, 1999).

22 Simpson KR, Knox GE: Obstetrical accidents involving intravenous magnesium sulphate: recommendations to promote patient safety. MCN Am J Matern Child Nurs 2004; 29:161-171.

23 Collaborative Eclampsia Trial: Which anticonvulsant for women with eclampsia? Evidence from the Collaborative Eclampsia Trial. Lancet 1995;345:1455-1463.
24 Duley L, Gulmezoglu AM, HendersonSmart DJ: Magnesium sulphate and other anticonvulsants for women with preeclampsia. Cochrane Database Syst Rev 2003;2: CD000025

25 Sibai BM: Magnesium sulphate prophylaxis in preeclampsia: Lessons learned from recent trials. Am J Obstet Gynecol 2004;190: 1520-1526.

26 Riaz M, Porat R, Broadsky NL, Hurt H: The effects of maternal magnesium sulphate treatment on newborns: a prospective controlled study. J Perinatol 1998;18:449-454.

27 The Magpie Trial Collaborative Group: A randomized trial comparing magnesium sulphate with placebo for pre-eclampsia. Outcome for children at 18 months. BJOG 2007;114:289-299.

28 Singh J, O’Donovan M, Coulter-Smith SD, Geary M: An audit of the use of magnesium sulphate in severe pre-eclampsia and eclampsia. J Obstet Gynaecol 2005;25:15-17.

29 Tuffnell DJ, Jankowicz D, Lindow SW, Lyons G, Russell IF, Walker JJ, Yorkshire Obstetric Critical Care Group: Outcomes of severe pre-eclampsia/eclampsia in Yorkshire 1999/ 2003. BJOG 2004;112:875-880.

30 Simon J, Gray A, Duley L: Cost-effectiveness of prophylactic magnesium sulphate for 9,966 women with pre-eclampsia from 33 countries: economic evaluation of the Magpie Trial. BJOG 2006;113:144-151. 